\title{
Retraction Note to: Intestinal Microbiota, Probiotics and Human Gastrointestinal Cancers
}

\author{
Antonella Orlando • Francesco Russo
}

Published online: 25 August 2013

(C) Springer Science+Business Media New York 2013

\section{Retraction to: J Gastrointest Canc (2013) 44:121-131 DOI 10.1007/s12029-012-9459-1}

The authors retract this article as it contains large sections of text duplicated from previously published articles, a without proper acknowledgement, including:

Asp, N. G.; Mollby, R.; Norin, L.; Wadstrom, T., 2004 Probiotics in gastric and intestinal disorders as functional food and medicine. Scandinavian Journal of Nutrition 48(1): $15-25$

Azcárate-Peril MA, Sikes M, Bruno-Bárcena JM. Am J Physiol Gastrointest Liver Physiol. 2011 Sep; 301(3):G401-24. DOI: 10.1152/ajpgi.00110.2011. Epub 2011 Jun 23. The intestinal microbiota, gastrointestinal environment and colorectal cancer: a putative role for probiotics in prevention of colorectal cancer?
Bosscher D, Breynaert A, Pieters L, Hermans N. J Physiol Pharmacol. 2009 Dec; 60 Suppl 6:5-11.Food-based strategies to modulate the composition of the intestinal microbiota and their associated health effects.

Davis CD, Milner JA. J Nutr Biochem. 2009 Oct; 20(10):74352. DOI: 10.1016/j.jnutbio.2009.06.001. Epub 2009 Aug 27. Gastrointestinal microflora, food components and colon cancer prevention.

Gianotti L, Morelli L, Galbiati F, Rocchetti S, Coppola S, Beneduce A, Gilardini C, Zonenschain D, Nespoli A, Braga M. World J Gastroenterol. 2010 Jan 14; 16(2):167-75. A randomized double-blind trial on perioperative administration of probiotics in colorectal cancer patients.

The authors accept full responsibility for the duplication and apologize to the Editor and readers, as well as to the authors of the original articles.

The online version of the original article can be found at http://dx.doi.org/ 10.1007/s12029-012-9459-1.

A. Orlando $\cdot$ F. Russo $(\bowtie)$

Laboratory of Experimental Biochemistry, National Institute for

Digestive Diseases, I.R.C.C.S. "S. de Bellis", Via Turi, 27,

70013 Castellana Grotte, Bari, Italy

e-mail: francesco.russo@irccsdebellis.it 